\title{
A dequação dos descritores em Ciências da Saúde para a indexação de dissertações acadêmicas, na área de doenças respiratórias
}

\author{
Patrícia Rosas ${ }^{1}$, Carlos Alberto Guimarães², LUiz Felippe J Údice 3 , \\ Carlos Alberto de Castro Pereira ${ }^{4}$, Else Benetti Marques Válio ${ }^{5}$
}

Introdução: 0 processo de indexação consiste em duas fases: primeira, identificar e representar o conteúdo intelectual de um documento; segunda, traduzir a análise do assunto para uma linguagem específica, utilizando descritores. Na biblioteca do Instituto de Doenças do Tórax da UFRJ, a indexação era realizada por meio de um vocabulário controlado - Decs (Descritores em Ciências da Saúde). 0 objetivo deste trabalho foi verificar se são adequados, para indexação, os descritores empregados pelos autores de teses e dissertações de mestrado, na área de doenças respiratórias. Método: Os descritores de 29 teses e dissertações de mestrado em Tisiologia e Pneumologia, de 1990 a 1996, foram estudados. Resultados: A coleta de dados evidenciou que 29 autores empregaram 101 descritores (3,48 descritores/ autor). Dos 101 descritores, 47 (47\%) eram adequados. Conclusão: Quarenta e sete por cento dos descritores empregados, nas teses e dissertações do Curso de Mestrado em Tisiologia e Pneumologia do IDT-UfRJ (1990 a 1996), são adequados segundo o DeCS. I Pneumol 1999;25(6):309-312)

\section{Suitability of Health Science key words for indexing master's degree theses and dissertations in the area of respiratory diseases}

Introduction: The process of indexing consisted of two phases: firstly, to identify and represent the intellectual contents of a document; and secondly, the translation of the subject analysis into a specified language, with the aid of key words. At the Instituto de Doenças do Tórax da UFRJ medical library, the indexing was performed through a controlled vocabulary - the MeSH (Medical Subject Headings). The purpose of this study was to identify if the authors' subject headings were adequate for indexing Master's degree theses and dissertations on respiratory diseases. Method: The key words of 29 Master theses and dissertations, from 1990 through 1996, were studied. Results: The data collection showed that 29 authors employed 101 key words (3.48 headings/author). Among the 101 key words, 47 (47\%) were adequate. Conclusion: Forty-seven per cent of the key words employed, on Master's degree theses and dissertations on respiratory diseases (IDT-UFRJ , 1990-1996), were adequate.

Sigla e abreviatura utilizada neste trabalho

DeCS - Descritores em Ciências da Saúde

$\mathrm{MeSH}$ - Medical Subject Headings

1. Bibliotecária do Instituto de Doenças do Tórax da Universidade Federal do Rio de J aneiro; Mestra em Biblioteconomia pela Pontifícia Universidade Católica de Campinas (Puccamp).

2. Professor Adjunto de Medicina da Universidade Federal do Rio de J aneiro.

3. Professor Titular de Medicina da Universidade Federal Fluminense.

4. Doutor em Medicina pela Universidade Federal de São Paulo.

5. Professora Doutora do Departamento de Pós-graduação em Biblioteconomia da Puccamp. Órgão financiador: Capes.

Endereço para correspondência - Patrícia Rosas, Instituto de Doenças do Tórax da Universidade Federal do Rio de J aneiro, Rua Carlos Seidl, 813, Caju - 20931-000 - Rio de J aneiro, RJ. Tel. (21) 58083361.

Recebido para publicação em 20/4/99. Reapresentado em 18/6/99. A provado, após revisão, em 29/9/99.
Descritores - Resumos e indexação. Descritores. Dissertações acadêmicas. Doenças respiratórias.

Key words - Abstracting and indexing. Key words. Dissertations, academic. Respiratory tract diseases.

\section{INTRODUÇÃO}

A contribuição de um pesquisador só termina quando sua pesquisa é divulgada para a comunidade científica. Para recuperar as informações, é necessário que os documentos sejam indexados, isto é, convertidos em linguagem documentária a partir da linguagem utilizada pelo autor.

Linguagens documentárias são os instrumentos que nos ajudam a representar o conhecimento de uma área específica, com o objetivo de fornecer aos usuários a informação contida nos textos ${ }^{(1)}$. 
As linguagens mais desenvolvidas, como os tesauros, são permanentemente atualizadas, mediante supressão de conceitos em desuso, reagrupamento de descritores raramente utilizados e adição de termos novos (2).

0 tesauro é uma linguagem documentária definida como lista estruturada de termos, empregada por indexadores, para descrever um documento, de modo a permitir a recuperação da informação(3).

Entende-se por estrutura do tesauro o relacionamento entre os conceitos rep resentados por termos, ou seja, nenhum termo pode figurar num tesauro sem que esteja ligado a outro. Esta ligação é determinada por seu significado(4).

Os tesauros - vocabulários controlados - médicos constituem o cerne das aplicações da informática na área da saúde. Estes vocabulários existem há mais de cem anos e visavam, inicialmente, à classificação das causas de morte. São exemplos: International Classification of Diseases, Medical Subject Headings (MeSH), Standard Nomenclature of Pathology (SNOP), etc. (5).

As palavras que descrevem um assunto com precisão são chamadas descritores ou termos preferidos(6).

Para o trabalho de indexação, na biblioteca do Instituto de Doenças do Tórax da U niversidade Federal do Rio de J aneiro (BIBLIDT-UFRJ), fez-se necessário utilizar um instrumento de normalização da linguagem. Optou-se pelo vocabulário Decs (Descritores em Ciências da Saúde), em virtude de sua importância na área médica.

O vocabulário DeCS foi criado pela BIREME para permitir a indexação e recuperação de assuntos nas bases LILACS e MEDLINE, a partir do MeSH (Medical Subject Headings) da US National Library of Medicine.

LILACS (Literatura Latino-A mericana e do Caribe em Ciências da Saúde) é uma base publicada, desde 1982, sob coordenação da BIREME - Centro Latino-A mericano e do Caribe de Informação em Ciências da Saúde.

MEDLINE é uma base da literatura internacional em Ciências da Saúde, produzida pela US National Library of Medicine e contém referências e resumos da literatura publicada em mais de 3.700 revistas internacionais, desde 1966.

O MeSH (do qual deriva o Decs) utiliza para a seleção de novos descritores os seguintes critérios: 1 ) freqüência da utilização do termo na literatura médica; 2) reconhecimento da necessidade de inclusão do termo por vários usuários; 3) recomendação de fazer constar determinados descritores por parte de conselheiros em terminologia; 4) clareza e concisão do termo ${ }^{(7)}$.

O Decs é editado em espanhol/ inglês e português/ inglês, com atualização anual. Contém não somente os descritores autorizados e seus sinônimos, mas também outras informações de interesse, como: qualificadores permitidos; categorias às quais o descritor pertence; descritores relacionados e notas explicativas, de coordenação, de uso de qualificadores e gerais.
O objetivo deste trabalho é verificar se são adequados, para indexação, os descritores empregados pelos autores de teses e dissertações de mestrado, na área de doenças respiratórias.

\section{Material e MÉTOdOS}

\section{A mostra}

O estudo compreendeu a análise dos descritores atribuídos pelos autores das teses e dissertações, no período de 1990 a 1996, na área de concentração em Tisiologia e Pneumologia, do curso de Mestrado do Instituto de Doenças do Tórax da Universidade Federal do Rio de J aneiro (IDT-UFRJ).

Dentre as 33 teses e dissertações defendidas, somente 30 foram inicialmente analisadas, porque três delas não se encontravam no acervo da biblioteca.

U ma tese foi excluída porque não apresentava nenhum descritor (tese no 19). Desse modo, 29 teses e dissertações consistiram na amostra deste estudo.

\section{Procedimentos}

Foi elaborado um protocolo com os seguintes itens: a) número da tese ou dissertação; b) sobrenome do autor; c) ano de defesa; d) descritores atribuídos pelos autores; e e) casela para receber a informação se determinado termo existe ou não no DeCs.

Os descritores das 15 teses e dissertações de 1990 a 1992 foram analisados para verificar se constavam ou não no DeCS, tendo como referência a primeira edição $(1988)^{(8)}$. Para os descritores daquelas 14 teses, defendidas de 1993 a 1996, foi utilizada a segunda edição $(1992)^{(9)}$.

Para que se considerasse um termo constante no DeCs, um critério foi estabelecido: possibilidade de recuperação online. P. ex., o termo "reação em cadeia da polimerase" (tese no 6) - o correto era REAÇÃO EM CADEIA POR POLIMERASE podia ser recuperado e por isso foi considerado como presente no DeCS. 0 mesmo aconteceu com o termo "SIDA/ AIDS" (tese no 26), que, embora escrito em português e inglês, podia também ser obtido apenas como SIDA.

Das 29 teses e dissertações, foram retiradas quatro (teses nos $15,26,27$ e 28 ) porque nelas todos os descritores empregados estavam no Decs.

Os resultados foram submetidos ao teste do qui-quadrado ${ }^{(10)}$.

\section{Resultados}

Os resultados, apresentados sob forma de quadros, são comentados no capítulo Discussão.

A análise dos 114 descritores, utilizados nas 29 teses e dissertações, está no Q uadro 1, onde cada descritor (grafado em letras maiúsculas) é avaliado pela letra "s", quando consta no DeCs - ou pela letra " $n$ ", quando não existe no DeCS (grafado em letras minúsculas). 


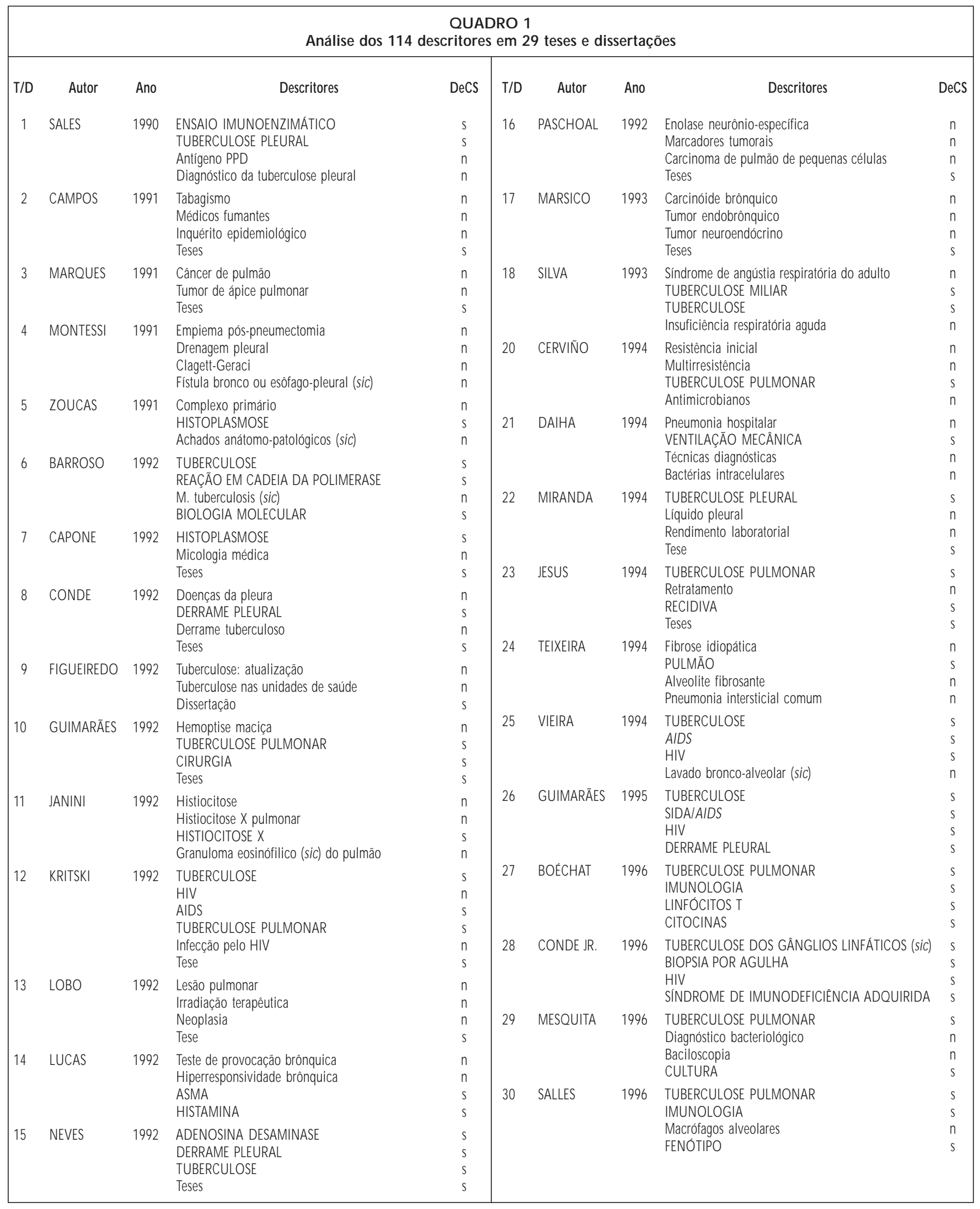




\section{DISCUSSÃO}

Com o objetivo de confrontar os resultados obtidos nesta pesquisa e aqueles eventualmente existentes na literatura, foi realizada uma busca bibliográfica nas bases de dados LILACS e MEDLINE (1994 a 1997), utilizando-se o descritor DESCRITORES.

Foram encontrados três trabalhos, embora nenhum deles com amostra e procedimentos iguais ao deste estudo.

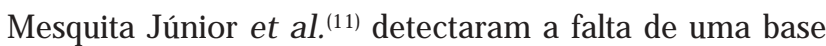
de dados que fosse útil para um levantamento bibliográfico na Disciplina de Homeopatia, visto que, àquela época, só existiam no Decs três termos referentes à especialidade. Os autores montaram um vocabulário de descritores homeopáticos, que foi incorporado pela BIREME, como uma nova categoria, ao Decs.

A zevedo et al. (7) estudaram 46 artigos publicados na Acta Cirúrgica Brasileira, no sentido de pesquisar o grau de adequação das propostas de indexação dos autores e daquelas feitas pela BIREME. Concluíram que: 1) os autores não consultaram 0 Decs com a intensidade que era desejável; 2) 0 DeCs ofereceu terminologia médica adequada para a indexação; entretanto, novos descritores mereciam ser incluídos, enquanto outros necessitavam revisão; 3) os indexadores da BIREME ressentiam-se da falta de embasamento especializado na área biomédica; 4) havia necessidade de os autores conhecerem melhor o Decs e de os indexadores da BIREME terem assessoria especializada na área biomédica.

Lowe e Barnett ${ }^{(12)}$ publicaram artigo sobre a utilização do Medical Subject Headings (MeSH) em buscas bibliográficas. Reviram a estrutura e o uso do MeSH, ressaltando como este vocabulário podia contornar as dificuldades da pesquisa na MEDLINE. Concluíram que a importância desta base e a tendência de os próprios usuários realizarem seus levantamentos bibliográficos tornavam crucial que os profissionais da saúde se familiarizassem com o MesH.

No VI Congresso de Pneumologia e Tisiologia do Rio de J aneiro, Rosas e Guimarães ${ }^{(13)}$ apresentaram pôster sobre a utilização do DeCs por autores de artigos em periódico nacional - J ornal de Pneumologia. Verificaram que nos fascículos, publicados em 1996, não havia menção de descritores em $29 \%$ dos trabalhos e que a metade dos descritores empregados não se encontrava no Decs.

A amostra desta pesquisa foi constituída pelas teses e dissertações defendidas no curso de Mestrado em Tisiologia e Pneumologia do IDT-UFRJ, as quais deviam obedecer às normas do FATED ${ }^{(14)}$.

A pós coleta inicial dos dados, verificou-se que 29 autores de teses e dissertações empregaram um total de 114 descritores (3,93 descritores/ autor).

No DeCs, o termo "teses" - não existia na forma singular - remetia para o descritor DISSERTAÇÕES ACADÊMICAS. Po- rém, este descritor só devia ser utilizado quando o assunto do trabalho a ser indexado tratasse de teses ou dissertações.

Nesta pesquisa, o termo "dissertação" foi considerado sinônimo de "teses". Assim, 13 (45\%) dentre os 29 autores utilizaram os termos "teses", "tese" e "dissertação", na elaboração das fichas catalográficas, obedecendo à normalização do FATED. Por esse motivo, esses termos foram excluídos de qualquer análise.

Deste modo, 29 autores atribuíram 101 descritores que foram objeto desta pesquisa (3,48 descritores/ autor).

Dentre os 101 descritores empregados pelos diversos autores, 47 (47\%) foram adequadamente utilizados. Neste caso, para $\mathrm{H}_{0}: \chi^{2}{ }_{0}=$ zero; $\mathrm{H}_{\mathrm{a}}: \chi^{2} \neq$ zero; $\mathrm{n}$. sig. $=0,05 ; \mathrm{g} . \mathrm{I}=1 ; \chi^{2}{ }_{\mathrm{c}}$ $=3,84$, foi obtido 0 valor de 0,48 . Isto quis dizer que não ocorreu diferença significante entre $o$ uso adequado e inadequado do Decs para efetivar a indexação.

Cabe ressaltar que as fichas catalográficas de todas as teses e dissertações foram elaboradas, exclusivamente, pelos autores e seus orientadores.

\section{CONCLUSÃO}

Q uarenta e sete por cento dos descritores empregados, nas teses e dissertações do Curso de Mestrado em Tisiologia e Pneumologia do IDT-UFRJ (1990 a 1996), são adequados segundo o Decs.

\section{REFERÊNCIAS}

1. Campos MLA. Linguagens documentárias: núcleo básico de conhecimento para seu estudo. R Esc Bibliotecon U niv Fed Minas Gerais 1995; 24:52-62.

2. Cintra AMM, Tálamo MFGM, Lara MLG, Kobashi NY. Para entender as linguagens documentárias. São Paulo: Polis/ APB, 1994.

3. Cavalcanti $C R$. Indexação \& tesauro: metodologia e técnicas. Brasília: Associação dos Bibliotecários do Distrito Federal, 1978.

4. Gomes HE. Manual de elaboração de tesauros monolíngües. Brasília: Programa Nacional de Bibliotecas das Instituições de Ensino Superior, 1990.

5. Cimino J J. Vocabulary and health care information technology: state of the art. J Am Soc Inf Sci 1995;777-779.

6. Austin D. Diretrizes para o estabelecimento e desenvolvimento de tesauros monolíngües. Brasília: IBICT, 1993.

7. Azevedo J LMC, Población DA, Goldenberg S. Descritores (unitermos) nos artigos científicos. Acta Cir Bras 1990;5:35-58.

8. DeCS - Descritores em Ciências da Saúde. São Paulo: Bireme/ O pas, 1988.

9. DeCS - Descritores em Ciências da Saúde. 2ạ ed. rev. atual. São Paulo: Bireme/ Opas, 1992.

10. Barbetta PA. Estatística aplicada às ciências sociais. Florianópolis: UFSC, 1994.

11. Mesquita J únior A, Cepeda LMR, Bella S. Indexação bibliográfica computadorizada em homeopatia: uma revolução no estudo e na pesquisa. Rev Homeopatia 1990;55:80-82.

12. Lowe HJ , Barnett GO. Understanding and using the Medical Subject Headings $(\mathrm{MeSH})$ vocabulary to perform literature searches. JAMA 1994;271:1103-1108.

13. Rosas $P, G$ uimarães $C A$. Descritores em ciências da saúde em periódico nacional. Pulmão-RJ 1997;6(Supl):41.

14. UFRJ. Formato e apresentação de teses ou dissertações de pós-graduação. Rio de J aneiro: UFRJ , 1979. 